\title{
More than memes: Embracing social media for 21st century supported employment
}

\author{
Robert Kimmel* \\ Rutgers University, The Boggs Center on Developmental Disabilities, New Brunswick, NJ, USA
}

Received 1 December 2020

Accepted 1 December 2020

\begin{abstract}
.
BACKGROUND: Employment specialists assist individuals with disabilities in obtaining and maintaining employment, but the majority of practitioners only utilize techniques, tools, and avenues established in specific research domains from over 20 years ago. New technologies, such as social media, are powerful tools employment specialists can utilize to assist individuals with disabilities seeking employment.

OBJECTIVE: This article provides context for why including social media into practice is important, what social media is, opportunities it can provide, and what social media platforms are best for employment specialists to use. This article explores how employment specialists can use Facebook, Twitter, and LinkedIn to find new opportunities, expand professional networks, and incorporate social media use into standard practices.

CONCLUSION: Social media is a powerful tool used extensively in talent recruitment. Supported employment professionals can use the identified strategies to help individuals with disabilities access employment opportunities in an increasingly digital world.
\end{abstract}

Keywords: Social media, supported employment, intellectual disabilities, developmental disabilities, networking, employment specialist, recruitment, LinkedIn, Facebook, Twitter

\section{Background}

Supported employment professionals, also known as employment specialists, hold a key role in disability services. Specifically, they are the professionals that assist individuals with disabilities in obtaining and maintaining gainful, meaningful employment. These professionals are expected to provide a wide range of individualized services (Cox \& Land, 2018) while managing large caseloads, scheduling issues, administrative tasks, uncoordinated systems communication, and tedious documentation requirements (Hall et al., 2018). Research shows that supported

\footnotetext{
*Address for correspondence: Robert Kimmel, Rutgers University, The Boggs Center on Developmental Disabilities, 335 George St, New Brunswick, NJ, USA. Tel.: +1 732235 8227; E-mail: robert.kimmel@rutgers.edu.
}

employment programs are effective in increasing employment rates of people with disabilities (Cimera, 2007), but the disparity between individuals with disabilities and those without remains significant across many key indicators including unemployment rate, retention rates, and dependence on federal financial support programs (Wehman et al. 2018).

To bridge this gap, we have seen an expansion in research and practice around school transition supports and adult supported employment programs, but the research continues to place a great deal of onus on the "competency and commitment" of the employment specialist (Havranek, 2005). There is an expectation for employment specialists to become "chameleons," adapting their practices and methodologies to the norms of the field, business, and stakeholders for the benefit of the supported job 
seeker or employee (Transition Resource Network \& Association for Persons Supporting Employment First, 2016). While this is accepted in current literature and practice, the majority of the technical, person-centered competencies, training, and tools provided to employment specialists find their roots in education, psychology, and sociology. These practices tend to focus on the improvement of the individual versus strategies that can be used in job searching, industry preparation, and business development. As a result, employment specialists have a limited repertoire of strategies and tools optimized to access gainful employment opportunities. For supported employment agencies and employment specialists to maximize the effects of their efforts finding meaningful employment for individuals with disabilities, there is a critical need to adapt practices to the current industry standards of finding and interacting with job candidates across labor markets. New strategies and tools can be identified by looking to the fields of business and Human Resources (HR) where the strategic potential of social media is increasing rapidly in talent recruitment (Nikolau, 2014) and knowledge sharing (Gibbs et al., 2013).

\section{Objective}

Business and HR literature indicate an increasing preference by companies to use social media sites for recruitment (Brotherton, 2012), selection and screening of candidates (Nikolau, 2014), in part due to the investment-to-return ratio (Jacobs, 2009). This preference is also seen in Fig. 1, analytics provided by the Jobvite Recruiter Nation Report (2016), showing how markedly recruiters use social media platforms to find talent. There is a stark contrast between this attention to social media in HR for businesses and current practices in supported employment. While the use of social media for supported employment has been discussed in disability literature over the last decade, practitioners do not report using social media to support the acquisition of gainful employment (Migliore et al., 2018). Research by Nikolau (2014) support this observed mismatch between recruiters and job seekers around social media, with recruiters turning to social media platforms to post jobs while job seekers choosing other means to search for leads. This disparity between recruiters present on social media platforms and job seekers searching for jobs in those spaces presents opportunities. The purpose of this article is to guide employment specialists in selecting

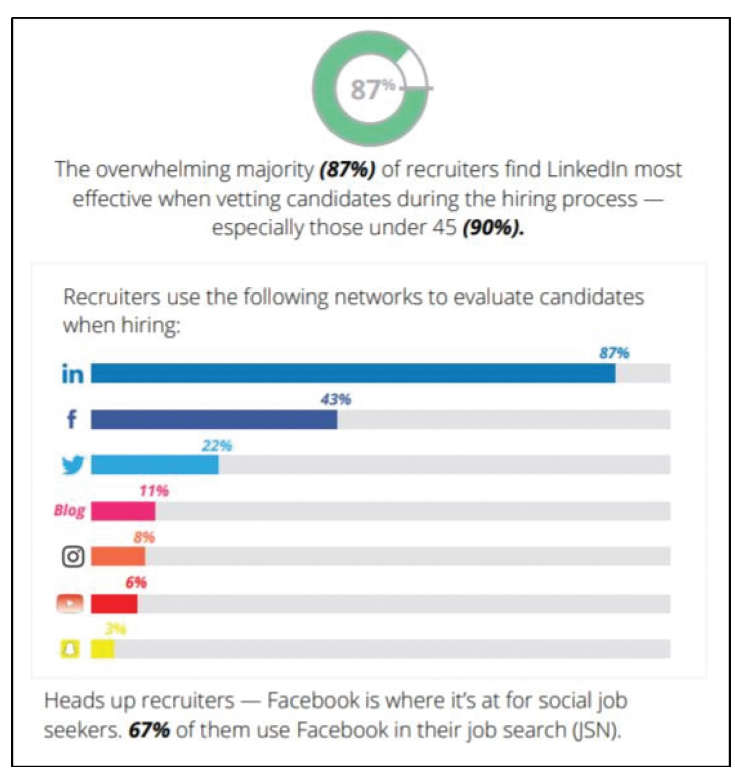

Fig. 1. Sourced from Jobvite Recruiter Nation Report (2016).

and using the social media platforms best able to take advantage of these opportunities in a dynamic job market.

\section{Method}

Social media is broadly defined as a category of online websites and applications that enable users to create and share content and/or participate in social networking (Kaplan and Haenlein, 2010). Many people associate social media with social applications such as Facebook, Twitter, LinkedIn, Snapchat, Instagram and more, but the reported use of social media is usually informal, such as the sharing of amusing memes, personal pictures, or anecdotal tweets. The broader definition of social media indicates that any website or application that allows you to provide feedback through likes or comments, share pictures or text, create a profile page, or have a username all indicate the presence of social media which greatly expands the scope. We live in an age of social media, with the Pew Research Center reporting over $65 \%$ of all adults engage in some form of social media (Perrin, 2015), $73 \%$ of all adults in the United States, and that $88 \%$ of marketers, amounting to over $\$ 60$ billion spent annually, use social media advertising and outreach (Gil-Or, 2010; Smith, 2011).

By utilizing specific social media platforms that show promise regarding talent recruitment and selection, employment professionals can become more effective in supporting a 21 st century job search. 
While many options exist, Facebook, Twitter, and LinkedIn are the social media platforms recommended for supported employment use, with data showing that these three platforms are most used by recruiters worldwide.

\subsection{LinkedIn}

Of all the social media platforms available, LinkedIn is the clear frontrunner for inclusion into supported employment practice. This completely business-oriented social networking site has over 300 million users with many recruiters and HR representatives in the population. With the ability to create an online profile that can't be commented on or tampered with, it allows users to safely host their resume for recruiters to find. With millions of jobs posted, interviews obtained, and jobs secured through the platform, this social media giant continues to perform admirably for job seekers worldwide. This social media platform should be the entry point for employment specialists utilizing social media for themselves, the individuals they support, and their supported employment program as a whole.

\subsection{Facebook}

Facebook is the most ubiquitous of social media platforms, with more than 1 billion active users worldwide. Pew Research Center shows in their 2016 study that almost $80 \%$ of all adults using the internet, and almost $70 \%$ of all adults in the United States, have and use Facebook. While this figure indicates a potential saturation of users for any employment opportunities found on Facebook, most users are unaware of Facebook's business connections and employment search capabilities. Facebook is a great resource for employment specialists, with the ability to search for jobs, connect with businesses, learn about target industries, and build networks. Over 65 million businesses have pages on Facebook and, as of February 15th, 2017, Facebook created the capability for businesses to create job postings and allow users to apply directly to these job opportunities using their Facebook accounts. This ability is also free for businesses to utilize, thereby attracting many small and local business owners to canvas for talent using the platform.

\subsection{Twitter}

Tweeting and retweeting has become familiar nomenclature in contemporary society, showing how broad Twitter's influence is in the general public. A micro-blogging social site with over 5,700 tweets sent every second, accounts are linked to individual people or businesses. Never before in history has it been as easy as it is today to directly contact a business, celebrity, or even the President of the United States all by using the power of social media. This gives employment specialists a unique tool with which to directly connect with business owners, perform research on company and individual values through tweets, and build synergistic networks with businesses as both a professional and representative of a supported employment agency.

\section{Results}

Employment specialists have two major consumers to work with, the job seeker and the employer/ business. Social media can be used in different ways to prepare, influence, and connect both entities, through direct and indirect means, with the following four strategies.

\subsection{Incorporating social media into intake and pre-placement processes}

Employment specialists should include social media as part of their initial assessment and Discovery Process. Questions/areas to address in the assessment could include:

A. Do you currently have any social media accounts?

1. Which ones? Who manages the account? Updates them? Posts to them?

2. If not, would you be open to creating a LinkedIn profile for the job search?

B. Using the account for the employment search

1. Does the individual understand privacy concerns around social media?

2. Does the individual know how to adjust privacy settings for shared content?

These questions give a baseline understanding of an individual's experience, comfort level and knowledge around social media. Employment specialists can work on creating LinkedIn profiles with their job seekers at the same time resumes are being reviewed. The information for both is the same and the LinkedIn profile will create another avenue for recruiters and job leads to find your candidate. Social media has many pros and cons that require education 
and practice to understand. This social media/internet/messaging curriculum is valuable social skills training that can be worked on throughout the supported employment process. Additionally, "scrubbing" current profiles is an additional skill that employment specialists can teach job seekers. Learning how to adjust privacy settings on personal content that you would not want a recruiter to see is a valuable skill that still allows for freedom of expression on personal social media accounts such as Facebook while professionalizing what a recruiter sees.

\subsection{Aggregating business information}

Facebook, Twitter, and LinkedIn all use algorithms to predict that content about which a user would like to see more. Every time a user likes a post, follows a person, or connects with a business, the platforms will begin to fill that user's news feed, suggested and prioritized messages or posts based on that history. This is a passive, but powerful way for employment specialists to use social media to gather a great deal of information on businesses, culture, language, growth, closings, news, and much more. On Facebook, "liking" local business pages will show an employment specialist more of that business and related business' posts, what other community events they take part in, if they are expanding, and job postings they may have hosted as just a few examples. Twitter allows employment specialists to "follow" and connect with business owners directly, and thereby see how those business owners communicate and what stances they take publicly. This allows the employment specialist to gauge the company culture and value sets. LinkedIn allows for similar aggregating of information by using the built in algorithms, "liking" posts by users or by "following" business pages.

While the previous methods are for an employment specialist to gather information quickly, this connection to businesses on these platforms can also be used from an organizational standpoint to build business trust in the employment specialist and the supported employment agency. Each of these platforms has the ability for employment specialists or supported employment agencies to "tag", or mention, businesses in public posts as well as "retweet" or "share" content that they have created. In this way, employment specialists can publicly celebrate a meaningful and professional connection with a community business, driving online traffic to the business and vice versa. These synergies are important and build lasting relationships that create mutual gain for all parties involved. Social media can make the job development component of supported employment that much easier.

\subsection{Expanding professional networks}

Traditional job development for an employment specialist is on-the-ground and face-to-face interactions with businesses owners and community stakeholders. This method of increasing professional employment networks is time consuming and reliant on the spontaneous communicative skill of the employment specialist. While social media is not a direct replacement in every instance for this kind of professional relationship cultivation, it can always supplement these interactions and, at times, replace the traditional form. Of the three target platforms, LinkedIn is especially good at building and sustaining professional networks. When employment specialists meet business owners and trade business cards, this action should also be mirrored on LinkedIn. Algorithms on LinkedIn connect users by "degrees of separation," with direct contacts being 1st tier contacts, their contacts being 2 nd tier contacts, with 3 rd tier being the farthest away that a user can contact. Every time an employment specialist adds a connection, the pool of professionals that can be sent a message expands. More connections and a larger networks place more information and opportunity at the fingertips of an employment specialist or job seeker. LinkedIn also sorts the professionals a user can connect with by industry and company as well. Employment specialists can use this information to "warm up" contacts, reaching out to previous connections that work in the industry or the company for insight into hiring practices or the best way to approach an opportunity.

\subsection{Exploring job postings}

While all three platforms have the capability to showcase job opportunities, LinkedIn has the most traditional design to searching job postings. Much like other popular job search engines like Monster.com or Indeed.org, jobs can be searched for by title, industry, salary, and a variety of other filters. These postings are paid for by businesses and tend to lean toward larger companies and suburban/urban areas. The drawback of these search engines is even when limiting distances in a search, results outside of the target area will appear in search results. 
Facebook's job portal allows for a very specific control of where a job seeker or employment specialist would look for opportunities. By placing a GPS point on a map, the user can expand and contract the radial distance of a circle around the point, looking only for opportunities posted in that area. This is an important point to consider in supported employment, with transportation reported in research as a primary barrier to accessing gainful employment opportunities. Other strengths of the Facebook job posting model are how a person uses the platform to apply. Job postings on Facebook do not require a resume but instead offer a thousand word text box to explain a job seekers interest and qualifications, confirming the application submission with a message into the user's Facebook Messenger. An important note is that special attention should be paid to updating information and privacy settings on a job seeker's Facebook account, as the application auto-populates from information from a user's profile.

\section{Conclusion}

Social media is here to stay and its influence continues to grow. It is important for supported employment professionals to adopt new technologies and methods used in other industries to keep job seekers with disabilities competitive in digital recruitment spaces and able to access employment opportunities, wherever they may appear. While literature has mentioned the need for social media interventions in the past, practitioners must begin to apply social media strategies like the ones mentioned in this article with consistency and intention. Social media is the key of the 21 st century employment specialist, one that opens doors to expansive employment possibilities for individuals with disabilities.

\section{Conflict of interest}

The author declares no conflict of interest.

\section{References}

Brotherton, P. (2012). Social media and referrals are best sources for talent. $T+D, 66(1), 24$.

Cimera, R. E. (2007). The cost-effectiveness of supported employment and sheltered workshops in Wisconsin: FY 2002-2005. Journal of Vocational Rehabilitation, 26(3), 153-158.
Cox, M. E., \& Land, K. A. (2019). The power of the employment specialist: Skills that impact outcomes. Journal of Vocational Rehabilitation, 50(3), 273-278. https://doi.org/10.3233/JVR191007

Gibbs, J. L., Rozaidi, N. A., \& Eisenberg, J. (2013). Overcoming the "ideology of openness": Probing the affordances of social media for organizational knowledge sharing. Journal of Computer-Mediated Communication, 19(1), 102-120. https://doi.org/10.1111/jcc4.12034

Gil-Or, O. (2010). Building consumer demand by using viral marketing tactics within an online social network. Advances in Management, 3(7), 7-14.

Hall, A., Butterworth, J., Winsor, J., Kramer, J., Timmons, J., \& Nye-Lengerman, K. (2018). Building an evidencebased, holistic approach to advancing integrated employment. Research and Practice for Persons with Severe Disabilities, 43(3), 207-218. https://doi.org/10.1177/1540796918787503

Havranek, J. E. (2005). Working relationships: Creating career opportunities for job seekers with disabilities through employer partnerships. Journal of Applied Rehabilitation Counseling, $36(2), 43$.

Jacobs, D. (2009), "Surviving the social explosion", Landscape Management, 48(12), 10-13.

Jobvite, Inc. (2016), Jobvite Recruiter Nation Report 2016. Retrieved November 30, 2020 from https://www.jobvite. com/wp-.content/uploads/2016/09/RecruiterNation2016.pdf

Kaplan, A. M., \& Haenlein, M. (2010). Users of the world, unite! The challenges and opportunities of social media. Business Horizons, 53(1), 59-68. https://doi.org/10.1016/ j.bushor.2009.09.003

Migliore, A., Nye-Lengerman, K., Lyons, O., Bose, J., \& Butterworth, J. (2018). A model of employment supports for job seekers with intellectual disabilities. Journal of Rehabilitation, 84(2), 3-13.

Nikolaou, I. (2014). Social networking web sites in job search and employee recruitment. International Journal of Selection and Assessment, 22(2), 179-189. https://doi. org/10.1111/ijsa.12067

Perrin, A. (2015). Social media usage. Pew Research Center, 5268.

Smith, K. T. (2011). Digital marketing strategies that millennials find appealing, motivating, or just annoying. Journal of Strategic Marketing, 19(6), 489-499.

Training Resource Network, Inc. and Association for Persons in Supported Employment (2010). APSE supported employment competencies. Retrieved November 30, 2020 from https://www.apse.org/wp-content/uploads/2014/01/APSESupported-Employment-Competencies11.pdf

Wehman, P., Taylor, J., Brooke, V., Avellone, L., Whittenburg, H., Ham, W., Brooke, A., \& Carr, S. (2018). Toward competitive employment for persons with intellectual and developmental disabilities: What progress have we made and where do we need to go. Research and Practice for Persons with Severe Disabilities, 43(3), 131-144. https://doi.org/10.1177/1540796918777730 